\title{
Levodopa/Carbidopa Intestinal Gel for Treatment of Advanced Parkinson's Disease: An Update on the Effects of Cognitive Functions
}

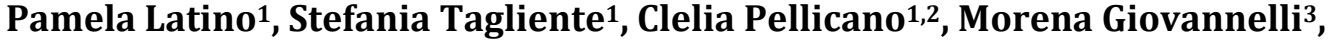 \\ Francesco E. Pontieri1,2 \\ ${ }^{1}$ Department of Neuroscience, Mental Health and Sensory Organs (NeSMOS), "Sapienza” University, Rome, Italy \\ ${ }^{2}$ Department of Clinical and Behavioral Neurology, "Santa Lucia Foundation” IRCCS, Rome, Italy \\ ${ }^{3}$ Unit of Neurology, Sant'Andrea Hospital, Rome, Italy \\ Email: fe.pontieri@gmail.com
}

How to cite this paper: Latino, P., Tagliente, S., Pellicano, C., Giovannelli, M. and Pontieri, F.E. (2017) Levodopa/Carbidopa Intestinal Gel for Treatment of Advanced Parkinson's Disease: An Update on the Effects of Cognitive Functions. Advances in Parkinson's Disease, 6, 13-23.

https://doi.org/10.4236/apd.2017.61002

Received: October 31, 2016

Accepted: February 5, 2017

Published: February 8, 2017

Copyright $\odot 2017$ by authors and Scientific Research Publishing Inc. This work is licensed under the Creative Commons Attribution International License (CC BY 4.0).

http://creativecommons.org/licenses/by/4.0/

\begin{abstract}
Cognitive impairment is a frequent non-motorsymptom of Parkinson's disease (PD). In early disease stage, this takes the features of dysexecutive syndrome, and is mostly dependent on derangement of frontostriatal circuitries. In advanced stages, worsening of dysexecutive symptoms is accompanied by disorientation and memory deficit leading to dementia in $30 \%$ of cases, due to multiple neurotransmitter derangement. Dysexecutive symptoms in the early stages of PD may benefit from dopamine replacement therapy (DRT). Conversely, severe cognitive symptoms in more advanced stages are frequently aggravated by DRT. In particular, pulsatile stimulation of dopaminergic receptors by orally administered levodopa (LD) plays a significant negative role on cognitive and neuropsychiatric symptoms in advanced PD. The introduction of a gel of LD-carbidopa for continuous intestinal administration (LCIG) allows marked stabilization of plasma LD concentrations and provides benefit on motor fluctuations and dyskinesia of significantly greater magnitude than conventional oral administration in advanced PD patients. The results from several preliminary studies suggest that efficacy of LCGI on motor symptoms may be accompanied by good tolerability and potential benefit on several non-motor symptoms, including cognitive impairment. Future studies with longer observation period and larger cohorts are advised to confirm these preliminary observations.
\end{abstract}

\section{Keywords}

Cognition, Dementia, Dopamine Replacement Therapy, Duodopa, Levodopa, Parkinson's Disease 


\section{Background}

The cardinal motor symptoms of Parkinson's disease (PD) (bradykinesia, rigidity, rest tremor) depend upon progressive degeneration of the dopaminecontaining neurons in the substantia nigra pars compacta [1]. The discovery of drugs replacing dopamine deficiency has a dramatic impact on quality of life and survival of PD patients [2]. After more than 40 years of use, levodopa (LD) remains the mainstream of pharmacological therapy for $\mathrm{PD}$, particularly in the advanced disease stage [3]. Long-lasting treatment with $\mathrm{LD}$, however, is associated with the occurrence of motor fluctuations and dyskinesia. Such sideeffects, defined as LD-long-term-syndrome (LTS), negatively affect quality of life of patients and caregivers [3] [4]. The pathogenesis of these motor complications is rather complex [5], depending on endogenous factors (age, disease duration, duration of LD treatment, irregular absorption of oral LD formulations) as well as pharmacokinetic and pharmacodynamic properties of LD. In particular, the relatively short plasma half-life of $L D$ and the pulsatile dopaminergic stimulation play a significant role in the development of LTS [4] [5]. To overcome these limits, a variety of therapeutic strategies have been introduced with the aim of ensuring more continuous and stable stimulation of post-synaptic dopaminergic receptors, including prolonged-release dopaminergic agonists, mono-aminooxidase-B inhibitors (MAO-i), and catechol-O-methyl-transferase inhibitors (COMT-i) [6].

More recently, a formulation of LD-carbidopa intestinal gel (LCIG) has been developed and applied to reduce fluctuations of plasma LD concentrations that follow oral administration of the drug (review in [7]). For long-term treatment, the gel is administered by means of a portable pump directly into the duodenum or upper jejunum by a permanent tube placed via percutaneous endoscopic gastrostomy. Treatment with LCIG is associated with significant reductions of motor fluctuations, "off" periods, and dyskinesia in advanced PD patients [8]. These positive effects on motor complications produce significant benefit on activities of daily living and quality of life of both PD patients and their caregivers [9].

\section{Cognitive Impairment in PD}

Besides of motor disturbances, PD patients frequently suffer from several nonmotor symptoms (NMS) including sleep disturbances [10], autonomic (gastrointestinal, cardiovascular, urogenital) [11], sensory [12], psychiatric (anxiety, depression, impulse control disorder and psychosis) [13], and cognitive [14] dysfunctions. Taken together, these NMS are associated with severe disability, shortened life expectancy, reduced quality of life of patients and caregivers, and increased health-care costs [15].

Cognitive dysfunction is relatively frequent in PD patients. In the early stages, cognitive impairment takes the features of the frontal subcortical syndrome, with impairment of attentional-executive, visual-spatial and working memory 
functions [16]. In more advanced stages, worsening of dysexecutive symptoms, disorientation and memory deficit drive to full-blown dementia in approximately $30 \%$ of cases [14]. Incidence of dementia in PD patients ranges $4-6$ times higher in comparison to otherwise healthy subjects [17]. Moreover, the majority of PD patients surviving more than 10 years develop symptoms of cognitive impairment with negative impact on daily activities [17].

Epidemiological studies contributed at identifying a number of risk factors for dementia in PD. Demographic features such as the subject's age, age at onset of motor symptoms, and disease duration are significant predictors of cognitive impairment in PD [18] [19] [20]. Several NMS, including neuropsychiatric (depression, hallucinations) and sleep disorders (REM sleep behavior disorder, RBD) [21] and cardiovascular autonomic failure [22] are positively associated with the development of dementia in PD. As to the motor features, cognitive deficit is significantly more frequent and severe in akinetic-rigid in comparison to tremor-predominant cases of PD [23]. Moreover, axial symptoms, in particular gait disturbances and postural instability, are positively associated with the occurrence and severity of cognitive deficits [23]. Some studies dealt with the relationship between body side of onset of motor symptoms and cognitive impairment in $\mathrm{PD}$, with rather contradictory results. Thus, motor lateralization does not influence cognitive features in early, unmedicated, stages of PD [16] [24]. Conversely, in more advanced stages, verbal dysfunctions are more frequent in subjects with right-limb onset and visual-spatial dysfunctions in those with left-limb onset of motor symptoms [25]. These latter results, which are in line with lateralization of some cognitive functions to the cerebral hemispheres, may also depend upon interaction between disease progression and chronic exposure to dopaminergic drugs, as discussed below.

The relationships between dopamine depletion and cognitive symptoms in PD are also the matter of controversy. Siepel et al. [26] reported that reduction of striatal tracer binding at DAT-Scan imaging was associated with executive but not visual-spatial or memory dysfunctions in early PD patients. Pathophysiological, neuropathologic and neuroimaging studies confirmed the presence of cognitive alterations in PD patients devoid of cortical pathology [27]-[33]. These findings, therefore, suggest that the basal ganglia dysfunction driven by nigrostriatal dopamine depletion may produce cognitive symptoms per se.

However, in older or more severely affected subjects other neurotransmitter/ receptor dysfunctions and pronounced cortical pathology may contribute to the cognitive deficit. Indeed, accumulation of alpha-synuclein positive Lewy bodies extends with disease progression from brainstem nuclei, including the substantia nigra pars compacta, to limbic and neocortical regions [34], and alterations of catecholamine (dopamine and norepinephrine), acetylcholine and glutamate neurotransmission have been identified in PD [35]. With this respect, Kehagia et al. [36] recently underlined the neuropsychological and clinical heterogeneity of cognitive impairment and dementia in $\mathrm{PD}$, and suggested that frontostriatal dysexecutive syndrome is primarily dependent on derangement of dopaminergic 
pathways, whereas non-dopaminergic (mostly cholinergic) pathology in extrastriatal regions causes memory and visual-spatial dysfunctions.

\section{The Influence of Dopaminergic Drugs on Cognitive Impairment in PD}

The identification of pathogenic mechanisms of cognitive dysfunction in PD is crucial for therapeutic management as well. Some studies showed the improvement of cognitive functions following dopamine replacement therapy (DRT) [37]-[44] particularly during early disease stages, whereas others suggested that DRT exerts deleterious effects [45]-[50]. Thus, DRT would be detrimental on subsets of cognitive functions mediating learning activities based on the integration of environment feedback with ongoing behavior. This dichotomy is somehow consistent with previous observations that DRT improves cognitive functions mediated by the dorsal striatum, such as selective attention, category judgment, time estimation, visual-spatial processing, implicit and explicit retrieval, set shifting and task switching [37] [39] [40] [51] but impairs functions mediated by the ventral striatum such as implicit and explicit learning, impulsivity, reversal learning and orienting to stimuli [52] [53] [54]. These neuropsychological findings parallel the different pathological involvement of the dorsal and ventral striatum in $\mathrm{PD}$. In fact, dopamine deficiency is significantly more pronounced in the dorsal striatum innervated by the substantia nigra pars compacta as compared to the ventral striatum innervated by the ventral tegmental area [55] [56] [57]. In accordance with these observations, MacDonald and Monchi [58] suggested that DRT improves cognitive functions mediated by the dopamine-depleted dorsal striatum but impairs other functions by over-stimulating the ventral striatum. Interestingly, these differences persist along disease course [56] [57], and may contribute at justifying the higher severity of neuropsychiatric and cognitive side effects of dopamine agonists in comparison to LD in older or more severely affected patients [59].

A further reason of interaction between DRT and cognitive functions in PD stems upon the observation that the number and functionality of dopaminergic terminals in the brain progressively reduces along disease course. This progression of damage limits the ability of surviving neurons to buffer extracellular dopamine (or levodopa) molecules and maintain synaptic dopaminergic activity within the normal range. In advanced PD stages, severe fluctuations of extracellular concentrations of dopamine may occur in relation to fluctuations of plasma levodopa concentrations that accompany oral administration. In turn, this may cause oscillations of dopaminergic synaptic activity with over-stimulation of post-synaptic receptors during the drug peak-dose phase and insufficient stimulation along the wearing-off phase.

As mentioned earlier, extensive research supports the hypothesis that pulsatile stimulation of post-synaptic dopaminergic striatal receptors by oral LD contributes at determining motor fluctuations and dyskinesia in the advanced stages of PD. Interestingly, fluctuations of NMS, including cognitive features, are relatively 
frequent in these patients [3] as if NMS symptoms during wearing-off may be related to drug-induced pulsatile stimulation of dopaminergic activity. Consequently, therapeutic management of the advanced stages of PD aims at optimizing the balance between positive and negative consequences of DRT on motor and non-motor functions.

On this basis, there is substantial background for considering continuous dopaminergic stimulation as a major goal for treatment of $\mathrm{PD}$ patients with motor and non-motor fluctuations [60]. In the majority of cases, adding/increasing third-generation dopamine agonists, MAO-i or COMT-i [61] are effective in reducing symptoms of LTS. In more advanced patients, however, alternative therapies such as deep brain stimulation (DBS) or continuous drug infusion are advised [61].

\section{Continuous Dopaminergic Stimulation in the Advanced Stages of PD: Effects on Cognitive Function}

Despite of their strong efficacy on motor complications, subcutaneous infusion of apomorphine and DBS of the subthalamic nucleus are frequently associated with the development or worsening of neuropsychiatric and cognitive symptoms [62] [63]. These non-motor complications may, indeed, pose contraindications to the above therapies.

Conversely, LCIG is less frequently associated with development or worsening of neuropsychiatric and cognitive complications. Indeed, recent studies reported improvement of NMS [64], including sleep disorders, fatigue, dysautonomic and cognitive symptoms following LCIG treatment in advanced PD patients.

Reports on the safety, tolerability and potential benefit of LCGI on cognitive functions in advanced PD patients are relatively recent. A retrospective study on 91 advanced PD patients co-suffering from hallucinations (65\%) and dementia (50\%) treated with LCIG in France [65] showed significant benefit on motor complications, quality of life and autonomy in $90 \%$ of cases without worsening of neuropsychiatric/cognitive symptoms. Similarly, another retrospective study [66] showed the safety and tolerability of 24-h infusion of LCIG on 21 advanced PD patients with severe night-time disability, the drop-out rate from treatment due to worsening of cognitive/neuropsychiatric symptoms being $<5 \%$. Sanchez Castaneda et al. [67] described the marked improvement of cognitive functions after switching oral therapy to LCIG infusion in two patients with PD with cognitive impairment, and Honig and coworkers [68] demonstrated the significant beneficial effect of LCIG on NMS, in particular attention and memory, in an observational study on 22 advanced PD patients monitored for 6 months. Finally, Zibetti and collaborators [69] performed a prospective study on 25 patients treated with LCIG for 3 years. Along the observation period, $41 \%$ of subjects developed cognitive impairment. Worsening of motor symptoms, in particular axial involvement both in "off" and "on" condition was the most significant predictor of dementia. However, there was no need for interrupting or reducing LCIG infusion in any of the enrolled subjects. 


\section{Conclusions and Future Perspectives}

Management of neuropsychiatric and cognitive deficits is an unmet need of the advanced stages of PD [70], with severe impact on daily functioning. The negative effects of DRT on neuropsychiatric and cognitive symptoms in advanced PD stages frequently prevent an optimal therapeutic management. Pulsatile stimulation of dopaminergic transmission by oral drugs (in particular LD) is a major determinant of motor and/or non-motor complications in the advanced stages of PD [5].

Consequently, research has focused on the development of therapeutic strategies aimed at ensuring continuous stimulation of dopaminergic transmission. In the case of $\mathrm{LD}$, this can be accomplished by infusing the drug directly into the gut through an external pump device. Indeed, switching to LCIG has been followed by marked reduction of the duration and severity of motor complications (both motor fluctuations and dyskinesia) in a large cohort of advanced PD patients [71]. From baseline to 12 weeks, there was a significant decrease in "off" time and significant increase in "on" time without troublesome dyskinesia in LCIG group when compared to immediate-release oral levodopa-carbidopa administration. These recent findings provided the first evidence that benefits of continuous LCIG delivery were of greater magnitude than those obtained with conventional medical therapies.

Studies on smaller cohorts showed good tolerability and safety of LCIG in PD patients with cognitive impairment, and provided initial evidence for beneficial effects of this procedure on cognitive and neuropsychiatric functions in advanced PD cases [65] [66] [67] [68] [69]. These observations support the conclusion by Merola and collaborators [72] that LCIG is the most preferable advanced therapy in PD patients with mild cognitive-behavioral impairment or more advanced age. Further studies with longer observational period and larger cohorts are advised to clarify whether the efficacy of LCIG on motor complications is accompanied by similar effects on NMS including cognitive and neuropsychiatric symptoms of the advanced stages of PD.

\section{Conflict of Interests}

Dr. Latino has been recipient of a research grant fellowship from Abbvie. The other Authors have no conflict of interest to declare.

\section{References}

[1] Hughes, A.J., Daniel, S.E., Kilford, L., et al. (1992) Accuracy of Clinical Diagnosis of Idiopathic Parkinson's Disease: A Clinic-Pathological Study of 100 Cases. Journal of Neurology, Neurosurgery and Psychiatry, 55, 181-184. https://doi.org/10.1136/jnnp.55.3.181

[2] Scherfler, C., Schwarz, J., Antonini, A., et al. (2007) Role of DAT-SPECT in the Diagnostic Work up of Parkinsonism. Movement Disorders, 22, 1229-1238. https://doi.org/10.1002/mds.21505

[3] Aquino, C.C. and Fox, S.H. (2015) Clinical Spectrum of Levodopa-Induced Complications. Movement Disorders, 30, 80-89. https://doi.org/10.1002/mds.26125 
[4] Encarnacion, E.V. and Hauser, R.A. (2008) Levodopa-Induced Dyskinesias in Parkinson's Disease: Etiology, Impact on Quality of Life, and Treatments. European Neurology, 60, 57-66. https://doi.org/10.1159/000131893

[5] Stocchi, F. (2009) The Hypothesis of the Genesis of Motor Complications and Continuous Dopaminergic Stimulation in the Treatment of Parkinson's Disease. Parkinsonism and Related Disorders, 15, S9-S15. https://doi.org/10.1016/S1353-8020(09)70005-7

[6] Stocchi, F., Tagliati, M. and Olanow, C.W. (2008) Treatment of Levodopa-Induced Motor Complications. Movement Disorders, 23, S599-S612. https://doi.org/10.1002/mds.22052

[7] Nyholm, D. (2012) Duodopa Treatment for Advanced Parkinson's Disease: A Review of Efficacy and Safety. Parkinsonism and Related Disorders, 18, 916-929. https://doi.org/10.1016/j.parkreldis.2012.06.022

[8] Antonini, A., Isaias, M., Canesi, M., et al. (2007) Duodenal Levodopa Infusion for Advanced Parkinson's Disease: 12-Month Treatment Outcome. Movement Disorders, 22, 1145-1149. https://doi.org/10.1002/mds.21500

[9] Nyholm, D., Nilsson Remahl, A.I., Dizdar, N., et al. (2005) Duodenal Levodopa Infusion Monotherapy vs Oral Polypharmacy in Advanced Parkinson's Disease. Neurology, 64, 216-223. https://doi.org/10.1212/01.WNL.0000149637.70961.4C

[10] Schrempf, W., Brandt, M.D., Storch, A., et al. (2014) Sleep Disorders in Parkinson's Disease. Journal of Parkinson's Disease, 4, 211-221.

[11] Goldstein, D.S. (2014) Dysautonomia in Parkinson's Disease. Comprehensive Physiology, 4, 805-826. https://doi.org/10.1002/cphy.c130026

[12] Cury, R.G., Galhardoni, R., Fonoff, E.T., et al. (2016) Sensory Abnormalities and Pain in Parkinson Disease and Its Modulation by Treatment of Motor Symptoms. European Journal of Pain, 20, 151-165. https://doi.org/10.1002/ejp.745

[13] Blonder, L.X. and Slevin, J.T. (2011) Emotional Dysfunction in Parkinson's Disease. Behavioural Neurology, 24, 201-217. https://doi.org/10.1155/2011/143857

[14] Emre, M., Ford, P.J., Bilgic, B. and Uc, E.Y. (2014) Cognitive Impairment and Dementia in Parkinson's Disease: Practical Issues and Management. Movement Disorders, 29, 663-672. https://doi.org/10.1002/mds.25870

[15] Prakash, K.M., Nadkarni, N.V., Lye, W.K., Yong, M.-H. and Tan, E.-K. (2016) The Impact of Non-Motor Symptoms on the Quality of Life of Parkinson's Disease Patients: A Longitudinal Study. European Journal of Neurology, 23, 854-860. https://doi.org/10.1111/ene.12950

[16] Pellicano, C., Assogna, F., Cravello, L., et al. (2015) Neuropsychiatric and Cognitive Symptoms and Body Side of Onset of Parkinsonism in Unmedicated Parkinson's Disease Patients. Parkinsonism and Related Disorders, 21, 1096-1100. https://doi.org/10.1016/j.parkreldis.2015.07.002

[17] Aarsland, D. and Kurz, M.W. (2010) The Epidemiology of Dementia Associated with Parkinson's Disease. Journal of the Neurological Sciences, 289, 18-22. https://doi.org/10.1016/j.jns.2009.08.034

[18] Giladi, N., Treves, T.A., Paleacu, D., et al. (2000) Risk Factors for Dementia, Depression and Psychosis in Long-Standing Parkinson's Disease. Journal of Neural Transmission, 107, 59-71. https://doi.org/10.1007/s007020050005

[19] Riedel, O., Klotsche, J., Spottke, A., et al. (2008) Cognitive Impairment in $873 \mathrm{~Pa}$ tients with Idiopathic Parkinson's Disease. Results from the German Study Group on Epidemiology of Parkinson's Disease with Dementia (GEPAD). Journal of Neurology, 255, 255-264. https://doi.org/10.1007/s00415-008-0720-2 
[20] Wang, Q., Zhang, Z., Li, L., Wen, H. and Xu, Q. (2014) Assessment of Cognitive Impairment in Patients with Parkinson's Disease: Prevalence and Risk Factors. Clinical Intervention in Aging, 12, 275-281.

[21] Anang, J.B., Gagnon, J.F., Bertrand, J.A., et al. (2014) Predictors of Dementia in Parkinson Disease: A Prospective Cohort Study. Neurology, 83, 1253-1260. https://doi.org/10.1212/WNL.0000000000000842

[22] Fanciulli, A., Strano, S., Colosimo, C., Caltagirone, C., Spalletta, G. and Pontieri, F.E. (2013) The Potential Prognostic Role of Cardiovascular Autonomic Failure in $\alpha$-Synucleinopathies. European Journal of Neurology, 20, 231-235. https://doi.org/10.1111/j.1468-1331.2012.03819.x

[23] Amboni, M., Barone, P. and Hausdorff, J.M. (2013) Cognitive Contribution to Gait and Falls: Evidence and Implications. Movement Disorders, 28, 1520-1533. https://doi.org/10.1002/mds.25674

[24] Erro, R., Santangelo, G., Picillo, M., et al. (2013) Side of Onset Does Not Influence Cognition in Newly Diagnosed Untreated Parkinson's Disease Patients. Parkinsonism and Related Disorders, 19, 256-259. https://doi.org/10.1016/j.parkreldis.2012.10.020

[25] Verreyt, N., Nys, G.M., Santens, P. and Vingerhoets, G. (2011) Cognitive Differences between Patients with Left-Sided and Right-Sided Parkinson's Disease: A Review. Neuropsychological Reviews, 21, 405-424. https://doi.org/10.1007/s11065-011-9182-x

[26] Siepel, F.J., Bronnick, K.S., Booij, J., et al. (2014) Cognitive Executive Impairment and Dopaminergic Deficits in De Novo Parkinson's Disease. Movement Disorders, 29, 1802-1808. https://doi.org/10.1002/mds.26051

[27] Monchi, O., Petrides, M., Doyon, J., Postuma, R.B., Worsley, K. and Dagher A. (2004) Neural Bases of Set-Shifting Deficits in Parkinson's Disease. Journal of Neuroscience, 24, 702-710. https://doi.org/10.1523/JNEUROSCI.4860-03.2004

[28] Monchi, O., Petrides, M., Strafella, A.P., Worsley, K.J. and Doyon, J. (2006) Functional Role of the Basal Ganglia in the Planning and Execution of Actions. Annals of Neurology, 59, 257-264. https://doi.org/10.1002/ana.20742

[29] Provost, J.S., Petrides, M. and Monchi, O. (2010) Dissociating the Role of the Caudate Nucleus and Dorsolateral Prefrontal Cortex in the Monitoring of Events within Human Working Memory. European Journal of Neuroscience, 32, 873-880. https://doi.org/10.1111/j.1460-9568.2010.07333.x

[30] Seger, C.A., Peterson, E.J., Cincotta, C.M., Lopez-Paniagua, D. and Anderson, C.W. (2010) Dissociating the Contributions of Independent Corticostriatal Systems to Visual Categorization Learning through the Use of Reinforcement Learning Modeling and Granger Causality Modeling. Neuroimage, 50, 644-656. https://doi.org/10.1016/j.neuroimage.2009.11.083

[31] Jellinger, K.A. (2010) Neuropathology in Parkinson's Disease with Mild Cognitive Impairment. Acta Neuropathologica, 120, 829-830. https://doi.org/10.1007/s00401-010-0755-1

[32] Adler, C.H., Connor, D.J., Hentz, J.G., et al. (2010) Incidental Lewy Body Disease: Clinical Comparison to a Control Cohort. Movement Disorders, 25, 642-646. https://doi.org/10.1002/mds.22971

[33] MacDonald, P.A., MacDonald, A.A., Seergobin, K.N., et al. (2011) The Effects of Dopamine Therapy on the Ventral and Dorsal Striatum-Mediated Cognition in Parkinson's Disease: Support from Functional MRI. Brain, 134, 1447-1463. https://doi.org/10.1093/brain/awr075 
[34] Braak, H., Del Tredici, K., Rub, U., de Vos, R.A.I., Jansen Steur, E.N.H. and Braak, E. (2003) Staging of Brain Pathology Related to Sporadic Parkinson's Disease. Neurobiology of Aging, 24, 197-211. https://doi.org/10.1016/S0197-4580(02)00065-9

[35] Francis, P.T. and Perry, E.K. (2007) Cholinergic and Other Neurotransmitter Mechanisms in Parkinson's Disease, Parkinson's Disease Dementia, and Dementia with Lewy Bodies. Movement Disorders, 22, S351-S357. https://doi.org/10.1002/mds.21683

[36] Kehagia, A.A., Barker, R.A. and Robbins, T.W. (2010) Neuropsychological and Clinical Heterogeneity of Cognitive Impairment in Patients with Parkinson's Disease. The Lancet Neurology, 9, 1200-1213. https://doi.org/10.1016/S1474-4422(10)70212-X

[37] Lewis, S.J.G., Slabosz, A., Robbins, T.W, Barker, R.A. and Owen, A.M. (2005) Dopaminergic Basis for Deficits in Working Memory but Not Attentional Set-Shifting in Parkinson's Disease. Neuropsychologia, 43, 823-832. https://doi.org/10.1016/j.neuropsychologia.2004.10.001

[38] Slabosz, A., Lewis, S.J.G., Smigasiewicz, K., Szymura, B., Barker, R.A. and Owen, A.M. (2006) The Role of Learned Irrelevance in Attentional Set-Shifting Impairments in Parkinson's Disease. Neuropsychology, 20, 578-588. https://doi.org/10.1037/0894-4105.20.5.578

[39] Torta, D.M.E., Castelli, L., Zibetti, M., Lopiano, L. and Geminiani, G. (2009) On the Role of Dopamine Replacement Therapy in Decision-Making, Working Memory, and Retard in Parkinson's Disease: Does the Therapy-Dose Matter? Brain and Cognition, 71, 84-91. https://doi.org/10.1016/j.bandc.2009.04.003

[40] Costa, A., Peppe, A., Dell'Agnello, G., et al. (2003) Dopaminergic Modulation of Visual-Spatial Working Memory in Parkinson's Disease. Dementia and Geriatric Cognitive Disorders, 15, 55-66. https://doi.org/10.1159/000067968

[41] Costa, A., Peppe, A., Dell'Agnello, G., Caltagirone, C. and Carlesimo, G.A. (2009) Dopamine and Cognitive Functioning in De Novo Subjects with Parkinson's Disease: Effects of Pramipexole and Pergolide on Working Memory. Neuropsychologia, 47, 1374-1381. https://doi.org/10.1016/j.neuropsychologia.2009.01.039

[42] Costa, A., Peppe, A., Brusa, L., Caltagiron, C., Gatto, I. and Carlesimo, G.A. (2008) Dopaminergic Modulation of Prospective Working Memory in Parkinson's Disease. Behavioural Neurology, 19, 45-48. https://doi.org/10.1155/2008/310437

[43] Costa, A., Peppe, A., Brusa, L., et al. (2008) Levodopa Improve Time-Based Prospective Memory in Parkinson's Disease. Journal of the International Neuropsychological Society, 14, 601-610. https://doi.org/10.1017/S135561770808082X

[44] Shohamy, D., Myers, C.E., Gehman, K.D., Sage, J. and Gluck, M.A. (2006) L-Dopa Impairs Learning, but Spares Generalization, in Parkinson's Disease. Neuropsychologia, 44, 774-784. https://doi.org/10.1016/j.neuropsychologia.2005.07.013

[45] Jahanshahi, M., Wilkinson, L., Gahir, H., Dharminda, A. and Lagnado, D.A. (2010) Medication Impairs Probabilistic Classification Learning in Parkinson's Disease. Neuropsychologia, 48, 1096-1103.

https://doi.org/10.1016/j.neuropsychologia.2009.12.010

[46] Feigin, A.S., Ghilardi, M.F., Carbon, M., et al. (2003) Effects f Levodopa on Motor Sequence Learning in Parkinson's Disease. Neurology, 60, 1744-1749. https://doi.org/10.1212/01.WNL.0000072263.03608.42

[47] Seo, M., Beigi, M., Jahashahi, M., et al. (2010) Effects of Dopamine Medication on Sequence Learning with Stochastic Feedback in Parkinson's Disease. Frontiers of Human Neuroscience, 4, pii: 36. 
[48] Ghilardi, M.F., Feigin, A.S., Battaglia, A., et al. (2007) L-Dopa Infusion Does Not Improve Explicit Sequence Learning in Parkinson's Disease. Parkinsonism and Related Disorders, 13, 146-151. https://doi.org/10.1016/j.parkreldis.2006.08.006

[49] Frank, M.J., Seeberger, L.C. and O’Reilly, R.C. (2004) By Carrot or By Stick: Cognitive Reinforcement Learning in Parkinsonism. Science, 306, 1940-1943. https://doi.org/10.1126/science.1102941

[50] Evans, A.H., Lawrence, A.D., Potts, J., et al. (2006) Relationship between Impulsive Sensation Seeking Traits, Smoking, Alcohol and Caffeine Intake, and Parkinson's Disease. Journal of Neurology, Neurosurgery and Psychiatry, 77, 317-321. https://doi.org/10.1136/jnnp.2005.065417

[51] Sohn, M.H., Ursu, S., Anderson, J.R., Stenger, V.A. and Carter, C.S. (2000) The Role of Prefrontal Cortex and Posterior Parietal Cortex in Task Switching. Proceedings of the National Academy of Sciences USA, 97, 13448-13453. https://doi.org/10.1073/pnas.240460497

[52] Dias, R., Robbins, T.W. and Roberts, A.C. (1996) Dissociation in Prefrontal Cortex of Affective and Attentional Shifts. Nature, 380, 69-72. https://doi.org/10.1038/380069a0

[53] Graef, S., Biele, G., Krugel, L.K., et al. (2010) Differential Influence of Levodopa on Reward-Based Learning in Parkinson's Disease. Frontiers of Human Neuroscience, 4, 169. https://doi.org/10.3389/fnhum.2010.00169

[54] Tomer, R., Aharon-Peretz, J. and Tsitrinbaum, Z. (2007) Dopamine Asymmetry Interacts with Medication to Affect Cognition in Parkinson's Disease. Neuropsychologia, 45, 357-367. https://doi.org/10.1016/j.neuropsychologia.2006.06.014

[55] Kish, S.J., Shannak, K. and Ornykiewicz, O. (1988) Uneven Pattern of Dopamine Loss in the Striatum of Patients with Idiopathic Parkinson's Disease. Pathophysiologic and Clinical Implication. New England Journal of Medicine, 318, 876-880. https://doi.org/10.1056/NEJM198804073181402

[56] Fearnley, J.M. and Lees, A.J. (1991) Ageing and Parkinson's Disease: Substantia Nigra Regional Selectivity. Brain, 114, 2283-2301. https://doi.org/10.1093/brain/114.5.2283

[57] Djaldetti, R., Lorberboym, M., Karmon, Y., Treves, T.A., Ziv, I. and Melamed, E. (2011) Residual Striatal Dopaminergic Nerve Terminals Nerve Terminals in Very Long-Standing Parkinson's Disease: A Single Photon Emission Computed Tomography Imaging Study. Movement Disorders, 26, 327-330. https://doi.org/10.1002/mds.23380

[58] MacDonald, P.A. and Monchi, O. (2011) Differential Effect of Dopaminergic Therapies on Dorsal and Ventral Striatum in Parkinson's Disease: Implications for Cognitive Function. Parkinson's Disease, 2011, Article ID: 522743.

[59] Zweig, R.M., Disbrow, E.A. and Javalkar, V. (2016) Cognitive and Psychiatric Disturbances in Parkinsonian Syndromes. Neurologic Clinics, 34, 235-246. https://doi.org/10.1016/j.ncl.2015.08.010

[60] Wright, B.A. and Waters, C.H. (2013) Continuous Dopaminergic Delivery to Minimize Motor Complications in Parkinson's Disease. Expert Review of Neurotherapeutics, 13, 719-729. https://doi.org/10.1586/ern.13.47

[61] Ferreira, J.J., Katzenschlager, R., Bloem, B.R., et al. (2013) Summary of the Recommendations of the EFNS/MDS-ES Review on Therapeutic Management of Parkinson's Disease. European Journal of Neurology, 20, 5-15. https://doi.org/10.1111/j.1468-1331.2012.03866.x

[62] Grandas, F. (2013) Subcutaneous Infusion of Apomorphine: A Reappraisal of Its Therapeutic Efficacy in Advanced Parkinson's Disease. Expert Review of Neurotherapeutics, 13, 1343-1353. https://doi.org/10.1586/14737175.2013.839235 
[63] Wu, B., Han, L., Sun, B.M., Hu, X.-W. and Wang, X.-P. (2014) Influence of Deep Brain Stimulation of the Subthalamic Nucleus on Cognitive Functions in Patients with Parkinson's Disease. Neuroscience Bullettin, 30, 153-161. https://doi.org/10.1007/s12264-013-1389-9

[64] Antonini, A., Yegin, A., Preda, C., Bergmann, L. and Poewe, W. (2015) Global Long-Term Study on Motor and Non-Motor Symptoms and Safety of Levodopa-Carbidopa Intestinal Gel in Routine Care of Advanced Parkinson's Disease Patients; 12-Month Interim Outcomes. Parkinsonism and Related Disorders, 21, 231-235. https://doi.org/10.1016/j.parkreldis.2014.12.012

[65] Devos, D. and French Duodopa Study Group (2009) Patient Profile, Indications, Efficacy, and Safety of Duodenal Levodopa Infusion in Advanced Parkinson's Disease. Movement Disorders, 24, 993-1000. https://doi.org/10.1002/mds.22450

[66] Busk, K. and Nyholm, D. (2012) Long-Term 24-H Levodopa/Carbidopa Gel Infusion in Parkinson's Disease. Parkinsonism and Related Disorders, 18, 1000-1001. https://doi.org/10.1016/j.parkreldis.2012.04.010

[67] Sanchez-Castaneda, C., Campdelacreu, J., Mirò, J., Juncadella, M., Jaumà, S. and Calopa, M. (2010) Cognitive Improvement after Duodenal Levodopa Infusion in Cognitively Impaired Parkinson's Disease Patients. Progress in Neuro-psychopharmacology and Biological Psychiatry, 34, 250-251. https://doi.org/10.1016/j.pnpbp.2009.10.021

[68] Honig, H., Antonini, A., Martinez-Martin, P., et al. (2009) Intrajejunal Levodopa Infusion in Parkinson's Disease: A Pilot Multicenter Study of Effects on Nonmotor Symptoms and Quality of Life. Movement Disorders, 24, 1468-1474. https://doi.org/10.1002/mds.22596

[69] Zibetti, M., Merola, A., Ricchi, V., et al. (2013) Long-Term Duodenal Levodopa Infusion in Parkinson's Disease: A 3-Year Motor and Cognitive Follow-Up Study. Journal of Neurology, 260, 105-114. https://doi.org/10.1007/s00415-012-6597-0

[70] Olanow, C.W. and Shapira, A.H. (2013) Therapeutic Prospects for Parkinson's Disease. Annals of Neurology, 74, 337-347. https://doi.org/10.1002/ana.24011

[71] Olanow, C.W., Kieburtz, K., Odin, P., et al. (2014) Continuous Intrajejunal Infusion of Levodopa-Carbidopa Intestinal Gel for Patients with Advanced Parkinson's Disease: A Randomized, Controlled, Double-Blind, Double-Dummy Study. The Lancet Neurology, 13, 141-149. https://doi.org/10.1016/S1474-4422(13)70293-X

[72] Merola, A., Zibetti, M., Angrisano, S., Rizzi, L., Lanotte, M. and Lopiano, L. (2011) Comparison of Subthalamic Nucleus Deep Brain Stimulation and Duodopa in the Treatment of Advanced Parkinson's Disease. Movement Disorders, 26, 664-670. https://doi.org/10.1002/mds.23524 
Submit or recommend next manuscript to SCIRP and we will provide best service for you:

Accepting pre-submission inquiries through Email, Facebook, LinkedIn, Twitter, etc. A wide selection of journals (inclusive of 9 subjects, more than 200 journals)

Providing 24-hour high-quality service

User-friendly online submission system

Fair and swift peer-review system

Efficient typesetting and proofreading procedure

Display of the result of downloads and visits, as well as the number of cited articles Maximum dissemination of your research work

Submit your manuscript at: http://papersubmission.scirp.org/

Or contact apd@scirp.org 